\title{
Mikael Agricolan Uuden testamentin painatusvaiheita
}

Jo pitkiä aikoja on mieltäni askarruttanut Mikael Agricolan Uuden testamentin Apostolien tekojen ja Roomalaisepistolan rajakohta. Edellisen teksti päättyy II, s. 393, ja tämän lehden kääntösivulla on kuvapiirros, jossa maapalloa kantava Kristus-lapsi polkee käärmeen päätä. Seuraava lehti on tyhjä, mutta sitä seuraavalla II, s. 397, on tittelilehti, jossa koristekehyksen keskellä on nimi "Se Pyhen Paualin Epistola Romarein tyge. 1548". Nämä silmiinpistävät erikoisuudet, kuva- ja tittelilehti keskellä UT:a, tuovat mieleen ajatuksen, ettei niitä ole ilman perusteita tähän kohtaan sijoitettu, vaan että niillä täytyy olla jokin erikoinen merkitys. Tosin olen kyllä jo ennenkin havainnut jotakin samanlaista. V:n 1642 Raamatussa on keskellä Vanhaa testamenttia Jesajan kirjan alussa erikoinen kuvallinen tittelilehti, johon liittyviä kysymyksiä tulin jo 40 vuotta sitten käsitelleeksi ensimmäisen suomalaisen Raamatun historiaa koskevassa tutkimuksessa. Erityisen nimilehden asettaminen tähän kohtaan on aiheutunut varmaankin siitä, että 1642:n Raamatun VT on jaettu neljään osaan, ja jokaisen osan alussa on tästä merkintä, mutta neljännen osan alussa on lisäksi kuparipiirros, joka on tavallista tälle Raamatulle ominaista tittelilehtityyppiä. Syynä nimilehden sijoittamiseen keskelle VT:a Jesajan kirjan alkuun on varmaankin se; että tämä on sisällyksen kannalta VT:n tärkein jakokohta. Siinä päättyvät historialliset kirjat ja alkavat profeetalliset kirjat. Puheena oleva nimilehti on kuitenkin nivelletty katkaisemista osoittamatta tähän

1 Niilo Ikola, Ensimmäisen suomalaisen Raamatun historiaa. Turun Historiallisen Yhdistyksen julkaisuja II, Turku 1927 s. $72-$ - 
kohtaan. Toisin näyttää sitä vastoin asianlaita olevan edellä mainit. tuun UT:n kohtaan sijoitetun kuvasivun ja nimilehden välillä. Tämä seikka antaakin aihetta UT:n painatushistorian yksityiskohtaiseen tarkasteluun. Kuvat 1 ja 2 s. 125.

Agricola oli ryhtynyt UT: $n$ suomentamiseen viimeistään jo kesällä 1537 opiskellessaan Wittenbergissä. ${ }^{2}$ Tämän työn hän näyttää saaneen päätökseen $1542 .{ }^{3}$ Ainakin jo joulukuun alussa 1543 käännös on ollut valmiina painettavaksi. Painatuksen aloittaminen kuitenkin viivästyi, kun hän ei saanut kuningas Kustaa Vaasalta anomaansa avustusta. Tilannetta valaisee Agricolan kamarineuvos Niilo Pietarinpojalle Tukholmaan 21.11.1547 lähettämä kirje ${ }^{4}$, jossa hän ilmoittaa, että suomenkielinen Uusi testamentti on juuri Tukholmassa kirjapainossa ja että hänen kappalaisensa Mikael Tapaninpoika on siellä valvomassa painatusta ja huolehtimassa oikaisuluvusta. Edelleen Agricola sanoo suuresti velkaantuneensa suomenkielisten kirjain vuoksi ja mạinitsee siinä erikoisesti UT:n. Tämä viittaa siihen, että kirjan painatus oli ollut jo ehkä pitkänkin aikaa käynnissä.

Painettavaksi ei kuitenkaan nähtävästi ensimmäiseksi otettu painetun Uuden testamentin alussa olevaa kymmenen lehden laajuista osaa, jossa on nimilehti, Uuden testamentin alkupuhe, luettelo UT:n kirjoista, toinen alkupuhe ja pyhän Matteuksen elämä Hieronymuksen mukaan. Näillä lehdillä on nimittäin aivan erillinen arkkimerkintä à-bij, eikä lehtien numeromerkintöjä ole ensinkään. Viimeiseltä sivulta 20 puuttuu Mätteuksen alkulehteen viittaava küstodí. Nimilehden vuosiluvusta 1548 ei myöskään työtä alettaessa 1547 vielä voinut olla täyttä varmuutta. Onhan nykyäänkin kirjoja painettaessa tavallista, että työtä ei aleta nimilehdestä, vaan se ja alkulause sekä usein sisällysluettelokin painetaan vasta myöhemmin. Voidaan siis pitää varmana, että UT:n näköispainoksen sivuja $1-20$ vastaavat lehdet on painettu myöhemmin, ehkä vasta koko varsinaisen UT:n valmistuttua.

Uuden testamentin painatustyö on ilmeisesti alettu Matteuksen evankeliumin varsinaisesta alusta. Ensimmäisen arkin merkiksi on yleisen käytännön mukaisesti otettu A-kirjain ja ensimmäisen lehden

2 A. I. Arwidsson, Handlingar till upplysning af Finlands häfder 6, s. 255.

Johannes Messenius, Scondia illustrata Tomus X, s. 25.

${ }^{4}$ Adolf Iwar Arwidsson, Handlingar 6, s. 267-268. 
numeromerkki on I. Arkit on taitettu kahdeksaan osaan. Viiden ensimmäisen lehden merkkeinä ovat A, Aij, Aiij, Aiiij ja Av. Arkin kolmessa viimeisessä lehdessä ei ole näitä merkintöjä. Arkkisarja A-Z sisältää 23 arkkia eli siis 184 lehteä. Tämän jälkeen oli otettava uusi arkkisarja, jonka ensimmäisen arkin merkiksi olisi vallitsevan käytännön mukaan kuulunut Aa. Näin onkin menetelty kaikissa niissä Agricolan kirjoissa, joissa on niin paljon lehtiä, ettei kirjainsarja A-Z ole riittänyt. Aa-merkintää on käytetty Rukouskirjassa I s. 369, Psalttarissa III s. 381 ja Weisut ja Ennustoxetteoksessa III s. 623 .

Kun tarkastelee UT:a tältä kannalta, niin huomaa heti, että siinä on kysymyksessä jokin normaalista poikkeava erikoistapaus. Painatustyön jatkamista varten onkin otettu vain puolen arkkia, ja sen merkkinä ei olekaan odotuksen mukainen Aa, vaan ainoastaan pieni a-kirjain. Nämä puolen arkin kahdeksan sivua on käytetty siten, että Apostolien tekojen loppuosan painamiseen on tarvittu vain viisi sivua. Kuudennella sivulla on kuva. Seitsemäs ja kahdeksas sivu ovat tyhjiä.

Tällainen puolen arkin käyttöönotto ja sen arkkisarjan poikkeuksellinen tunnus, pieni a, ovat merkittäviä. Ne osoittavat, että oli päätetty olla jatkamatta UT:n painatustyötä yhtämittaisesti ja keskeyttää se toistaiseksi Apostolien tekojen valmistuttua. Muussa tapauksessa olisi tietenkin otettu kokonainen 16-sivuinen arkki ja Apostolien tekojen jälkeen jatkettu työtä Roomalaiskirjeestä. Arkin merkki olisi luonnollisesti määrätty myös yleisen käytännön ja muissa Agricolan kirjoissa noudatetun tavan mukaisesti.

Selvänä osoituksena siitä, ettei painatustyötä aiottu välittömästi jatkaa Apostolien tekojen tekstin päätyttyä, on vielä huomattava, että viimeisen sivun 393 lopussa ei ole seuraavan sivun alkuun viittaavaa kustodia.

Edelleen joutuu kysymään, miksi painatustyö yleensä keskeytettiin ja miksi se tapahtui juuri edellä mainitussa kohdassa. Töiden keskeyttämisen syyksi voi ajatella monia eri mahdollisuuksia: Ei ollut riitțävästi painettavaksi valmista käsikirjoitusta. Oli vaikeata järjes-s tää suomen kieltä taitavan painatuksen valvojan ja korrehtuurin lukijan työskentelyä Tukholmassa. Ei ollut tarpeeksi työkustannuksien suorittamiseen tarvittavia rahavaroja, tai kirjapainolla oli liian paljon muita töitä. Jos UT:n painatụtöiden seisauttaminen olisi pantu 
toimeen tällaisista syistä, niin se olisi saattanut tapahtua missä UT: $n$ kohdassa tahansa. Kun nyt työn keskeyttämisen kohdaksi otettiin Apostolien tekojen ja Roomalaiskirjeen vaihdekohta, niin se ilmeisesti johtui siitä, että tämä on UT:n kahden pääosan, nim. historiallisten kirjain ja apostolien kirjeiden rajakohta.

Tämä on Agricolan omakin käsitys tästä UT:n jakokohdasta. Sitä osoittaa se, että hän on Apostolien tekojen alkuun merkinnyt sen nimeksi: Apostolein Teghot / quin on / Se Toinen Cappale Pyhẽ Lucan Euangeliumist. Hän lukee siis Apostolien teot kiinteästi evankeliumeihin kuuluvaksi. Apostolien tekojen ja Roomalaiskirjeen rajakohta sattuu samalla jokseenkin keskelle Uutta testamenttia. Alkuosa Matteuksen evankeliumin alusta lukien käsittää 187 lehteä ja loppuosa Roomalaiskirjeestä alkáen 163 lehteä.

Uuden testamentin jakaminen tällä tavalla kahteen osaan perustuu käsittääkseni siihen, että tähän asti painettu osa muodosti jonkinlaisen sopivan kokonaisuuden. Kun koko UT:n valmistuminen käsitellyistä syistä näytti viivästyvän, niin tahdottiin mahdollisimman pian saada edes osa siitä julkisuuteen tyydyttämään ilmeisesti suurta suomalaisen Raamatun, ensi sijassa UT:n tarvetta.

Ei ole mitään suoranaista tietoa siitä, milloin UT:n painatustyö keskeytettiin. Tuntuisi kuitenkin luonnolliselta olettaa sen tapahtuneen ennen, kuin kulkuyhteydet Tukholmasta Turkuun talven ajaksi kokonaan katkesivat, siis jo vuoden 1547 puolella. Olihan monestakin syystä tärkeätä, että Agricolan painatuksen valvojaksi ja oikaisulukijaksi lähettämä hänen kappalaisensa Mikael Tapaninpoika pääsi Suomeen ennen talven tuloa. Tarkoituksenmukaista oli tietenkin myös keskeyttää painatustyö siksi ajoissa, että siihen mennessä valmistunutta UT:n osaa voitaisiin viedä Suomeen ainakin jokin määrä, ennen kuin se kävisi mahdottomaksi jääesteiden takia.

Kun vuoden 1548 puolella kulkuyhteydet Tukholman ja Turun välillä taas avautuivat, niin ruvettiin $U T: n$ painatustyötä jatkamaan Roomalaiskirjeen alusta. Tällöin tietenkin otettiin käyttöön kahdeksanlehtinen kokoarkki, josta alkoi uusi arkkimerkintä $\mathrm{Aa}, \mathrm{Bb}$ jne. On erikoisesti pantava merkille, ettei välittömästi jatkettu painatustyötä Roomalaiskirjeen tekstillä, vaan sen alkuun sijoitettiin tähän kohtaan kuuluva nimilehti. Tässä nimilehdessä on koristeellinen kehyskuvio. Jonkinlainen koristekehys on muuten kaikkien Agricolan teosten nimilehdessä. Tämä kuvio on jäljennös piirroksesta, jonka tekijä on 
saksalainen Georg Lemberger. ${ }^{5}$ Hän oli erikoisesti Raamattujen kuvittajana ansioitunut taiteilija. Kuvassa on pilarien kannattama otsikko ja lukuisia enkelihahmoja. Tittelilehden keskiaukiolla on nimi: Se Pyhen Paualin Epistola Romarein tyge. 1548.

Erikoisen nimilehden asettaminen tähän kohtaan tietenkin osaltaan tehostaa edellä esitettyjä havaintoja UT:n jakamisesta kahteen osaan.

Tutkittavaksi nousee myös kysymys, onko vanhaa kirjallisuuttamme käsittelevissä teoksissa joitakin mainintoja Agricolan Uuden testamentin ilmestymisestä kahtena osana siten, että alkuosa julkáiśtiin ensin erillisenä kirjana. Olen tarkastanut Agricolan Uutta testaménttia koskevia tietoja vanhan kirjallisuutemme tärkeimmistä luetteloista. Niitä ovat laatineet mm. C. N. Keckman ${ }^{6}$, Fred. Wilh. Pipping ${ }^{7}$, Volter Kilpi ${ }^{8}$, Gustaf Adde ${ }^{9}$ ja Isak Collijn..$^{10}$ Heidän UT:a koskevat selontekonsa eivät kuitenkaan sisällä minkäänlaista mainintaa siitä, että UT olisi julkaistu kahtena osana.

Agricolan työtä suomalaisten kirjain julkaisijana tutkineista mainittakoon ensinnä piispa Jaakko Gummerus ${ }^{11}$, joka on kirjoittanut mm. Agricolan elämäkerran. Siinä ei kuitenkaan ole mitään huomautusta käsiteltävänä olevasta UT:n painatusvaiheesta. Professori A. F. Puukko ${ }^{12}$ on julkaissut laajan Suomalainen Raamattumme-nimisen teoksen, jossa hän käsittelee monipuolisesti UT:n käännöstyötä ja painatusta, mutta mitään viittausta UT:n kahtena osana ilmestymiseen tässäkään teoksessa ei ole.

5 Isak Collijn, Sveriges bibliografi intill år 1600. Band II Uppsala 19271931, s. 162.

${ }^{6}$ C. N. Keckman, Förteckning å härtils vetterligen tryckta Finska Skrifter, ¿bo 1821.

` Fred. Wilh. Pipping, Luettelo Suomeksi präntätyistä kirjoista, Helsingissä. $1856-57$.

\& Volter Kilpi, Suomenkielisen kirjallisuuden varhaispainokset vuoteen 1642. Iistoriallisia tutkimuksia. Turun Historiallinen Yhdistys. Turku 1924.

๑. Gustaf Adde, Äldre finskspråkiga skrifter i svenska Bibliotek. Bibliotekshistoriska Studier tillägnade Isak Collijn, Uppsala 1925.

10 Isak Collijn, Sveriges bibliografi intill âr 1600, Band II, Uppsala 19271931.

11 Jaakko Gummerus, Mikael Agricola. Jyväskylä 1908.

12 A. F. Puukko, Suomalainen Raamattumme, Helsinki 1946. 
Suomalaisen Raamatun käännöshistoriaa: on käsitellyt myös suomalaisen tieteen suurmies Henrik Gabriel Porthan, joka julkaisi 1778 tutkielman Kortt Historia om Finnska Bibel-Öfwersättningen. Tässä kirjoituksessa on Mikael Agricolan Uudesta testamentista seuraava tiedonanto: ${ }^{13}$ "Den skickelige och förtjente Biskopen i Åbo M. Michael Agricola företog sig altså, då han ännu war Rector eller Scholemästare derstedes, at först uttolka det Nya Testamentet, såsom aldranödwändigast; och denna öfwersättning utkom 1548 i Stockholm i. 4:o, uti twänne delar, af Amund Larssons tryckeri."

Tähän Porthanin kirjoitukseen varmaankin perustuu myös Reinhold Hertzbergin 1842 ilmestyneessä kirjasessa "Suomalaisista Biblioista" s. 6 oleva lausuma: "Hänen (Agricolan) toimestansa Uusi Testamenti ensimmäisen kerran Suomeksi präntistä uloskäwi vuonna 1548. Tämä kirja präntättiin Tukhulmisa Amund Lauritsan pojalta. Se ulosannettiin kahdesa osasa, neljänys-arkin suuruudesa."

Porthanin edellä mainittu tiedonanto, että Agricolan UT:n suomennos julkaistiin kahtena osana, on hyvin suppea, vain pelkkä toteamus. Siinä ei ole esitetty mitään selvitystä siitä, mihin tämä tieto perustuu. Ei myöskään ole osoitettu, mikä on ollut syynä kirjan kahtena osana ilmestymiseen ja mikä on ollut eri osien jakokohta. On tietenkin mahdollista; että kysymyksessä saattaa olla jokin vanha perimätieto, suullinen tai kirjallinen, joka Porthanin aikoihin asti on säilynyt Turun akatemian kirjastossa tai sen hoitajien tiedossa.

Voihan olla mahdollista, että silloisessa Turun akatemian kirjastossa on ollut sellainen tai sellaisia Agricolan Uusia testamentteja, jotka on sidottu kahteen eri osaan tai joista muuten on käynyt selville kirjan ilmestyminen kahtena osana.

Porthanin käytettävissä on tietenkin ollut myös Turun piispan Carl Fredrik Mennanderin (sittemmin Uppsalan arkkipiispa) kirjasto. Tästä kirjastosta Porthan sanoo, että siinä on täydellisin kokoelma suomalaisten seurakuntien hyväksi julkaistuja kirjoja. ${ }^{14}$ Mennanderin kuoleman (1786) jälkeen hänen kirjastonsa. myytiin huutokaupalla Uppsalassa 1788. Painetusta huutokauppaluettelosta ${ }^{15}$ käy ilmi, että tähän kirjastoon kuuluivat mm. tämän kirjoituksen kannalta tärkeät

13 Tidningar Utgifne Af et Sällskap i Åbo, n:o 12, 30. 6. 1778.

14 Tidningar Utgifne Af et Sällskap i Åbo, n:o 14, 30. 7. 1778.

15 Bibliotheca Caroli Frider. Mennander Publica auctione Vendenda Upsaliæ. D. 2 Februari, 1788. Upsala Univ. Bibliotek. 
Agricolan teokset Se Wsi Testamenti, Dauidin Psaltari, Weisut ja Ennustoxet ja Ne Prophetat Haggai. SacharJa. Maleachi. Näin ollen Mennanderin kirjasto on saattanut tarjota Porthanille aivan yhtä hyvät, ehkäpä paremmatkin mahdollisuudet kyseessä olevien tietojen lähteiksi kuin Turun yliopiston kirjasto.

Porthanilla oli omassakin kirjastossaan Agricolan Se Wsi Testa: menti ja myös muut edellä Mennanderin kirjastosta mainitut Agricolan teokset. Nämä kaikki sisältyvät 1812 julkaistuun Porthanin kirjain luetteloon. ${ }^{16}$ Nykyään tämä vielä sangen hyväkuntoinen Se Wsi Testamenti on Helsingin yliopiston kirjastossa. Olen sen tarkastanut, mutta en ole saanut siitä mitään lisäselvitystä tutkittavana olevaan asiaan.

Porhanin Tidningar Utgifne af et Sällskap i Åbo-lehdessä esittämä tieto, että Agricolan UT on ilmestynyt kahtena osana, näyttää jääneen myöhemmiltä polvilta unohduksiin. Niinpä edellä mainitut Agricolan kirjallisen tuotannon ja elämäkerran tutkijat eivät mainitse siitä mitään. Ehkäpä tuo vain vuosina $1771-78$ ja 1782—85 ilmestynyt lehti on ollut siksi vähän tunnettu, etteivät myöhemmät tutkijat ole tulleet kiinnittäneeksi siihen huomiota. Mahdollisesti Porthanin tiedonantoa, johon ei liity mitään perusteluja, ei ole pidetty luotettavana, varsinkin kun missään muualla ei liene tavattu vastaava mainintaa. Tämä Porthanin antama tieto on kaikessa suppeudessaan merkittävä, sillä on lähdettävä siitä, että hänellä on ollut tähän lausumaan riittävät peruste t, mitkä ne sitten lienevätkin. Se tukee ja vahvistaa olennaisesti edellä esittämiäni havaintoja ja niiden pohjalla tehtyä pääteImää, että Agricolan UT on ilmestynyt kahtena osana.

Tätä kysymystä käsiteltäessä on syytä koettaa tutkia, voísiko ehkä Agricolan kirjoista löytää jotakin hänen omasta kädestänsä peräisin olevaa UT:a koskevaa tietoa, jolla olisi tässä suhteessa merkitystä. Psalttarin esipuheessa hän luettelee siihen asti julkaisernansa teokset, mutta UT:sta sanotaan vain, että se painettiin Rukouskirjan jälkeen, mutta ei sen enempää. Paljon kiintoisampia ovat seuraavat Agricolan 1552 ilmestyneen teoksen Ne Prophetat. Haggai. SacharJa. Maleachi. alkupuheen (III s. 714) säkeet:

\footnotetext{
${ }^{16}$ Catalogus librorum quos possedit B. M. Vir Henr. Gabr. Porthan. Subhastatione publica die mensis Octobris 14 et sqq. anni 1812 Aboae dividendorum. Aboae.
} 
SE Mulloin Dauidin Psaltaris

Tapactui / nin mös Prophetais.

Joista silloin ne Colmet ieit

prentemet / Taluen estet sen teit.

Agricolan sanonta tässä runoasussa ei ehkä ole yhtä täsmällisen selvä, kuin se olisi suorasanaisessa muodossa. On kuitenkin ilmeistä, että Agricola tarkoittaa tässä sitä, että profeettain kirjoja painettaessa sattui samanlainen tapahtuma, kuin jo aiemmin oli sattunut Davidin Psalttaria julkaistaessa. Millainen tämä tapahtuma oli, saadaan parhaiten selville tarkastelemalla profeettain kirjain painatusvaiheita. Painatustyö alettiin Tukholmassa Amund Lauritsanpojan kirjapainossa 1551. Syksyllä rupesi kuitenkin nạyttämään selvältä, että koko teosta ei ehdittäisi saada valmiiksi, ennen kuin talven tulo katkaisisi kulkuyhteydet Tukholmasta Turkuun. Tämä johti työn keskeyttämiseen. Kun kuitenkin suurin osa oli myöhäissyksystä jo painettu, niin meneteltiin siten, että teos päätettiin julkaista kahtena eri osana. Profeettain I osa Weisut ja Ennustoxet Mosesen Laista ja Prophetista Wloshaetut valmistui marraskuun 5. p:nä 1551. Jäljellä olevien kolmen profeetan kirjan painatustyötä jatkettiin sitten seuraavana vuonna, ja elokuussa 1552 saatettiin julkaista loppuosa $\mathrm{Ne}$ Prophetat. Haggai. SacharJa. Maleachi. Mikäli Psalttarin painatusvaiheet olisivat olleet samanlaiset kuin profeettain, niin Psalttarin I osan olisi täytynyt ilmestyä syksyllä 1550 eri kirjana, ja toisen osan painatusta olisi jatkettu seuraavana keväänä, joten se olisi ilmestynyt 1551. Psalttaria tutkistellessani en ole huomannut ainakaan mitään ulkonaista merkkiä, joka viittaisi siihen, että se olisi ilmestynyt kahtena osana ja että sen painatustyö olisi jakautunut kahdelle vuodelle. Mm. arkkijako on katkeamaton, eikä kustodien merkitsemisessä ole mitään normaalista poikkeavaa. Ei myöskään ole johonkin jakokohtaan viittaavia kuva- tai nimilehtiä.

Psalttarin painatushistoriaan luovat valoa myös eräät asiakirjoissa säilyneet tiedot. Agricolan kirjanpainaja Amund Lauritsanpojalle lähettämästä, huhtikuun 1: senä 1551 päivätystä kirjeestä ${ }^{1 \tau}$ käy ilmi, että Psalttaria silloin parhaillaan suomennettiin, mutta ettei kuitenkaan enää ollut paljon kääntämättä. Tämän johdosta Agricola pyysi Amund Lauritsanpoikaa tiedustelemaan maisteri Olavi Pieta-

17 Adolf Iwar Arwidsson, Handlingar 6, s. 318-319. 


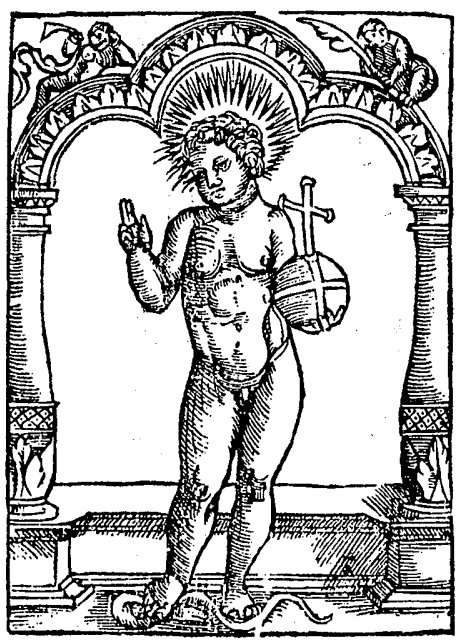

Kuva 1

Apostolien tekojen ja Weisut ja Ennustoxet -teoksen loppusivu

Kuva $\mathscr{2}$

Roomalaiskirjeen nimiösivu

Kwva 3

Ne Prophetat-teoksen nimiösivu
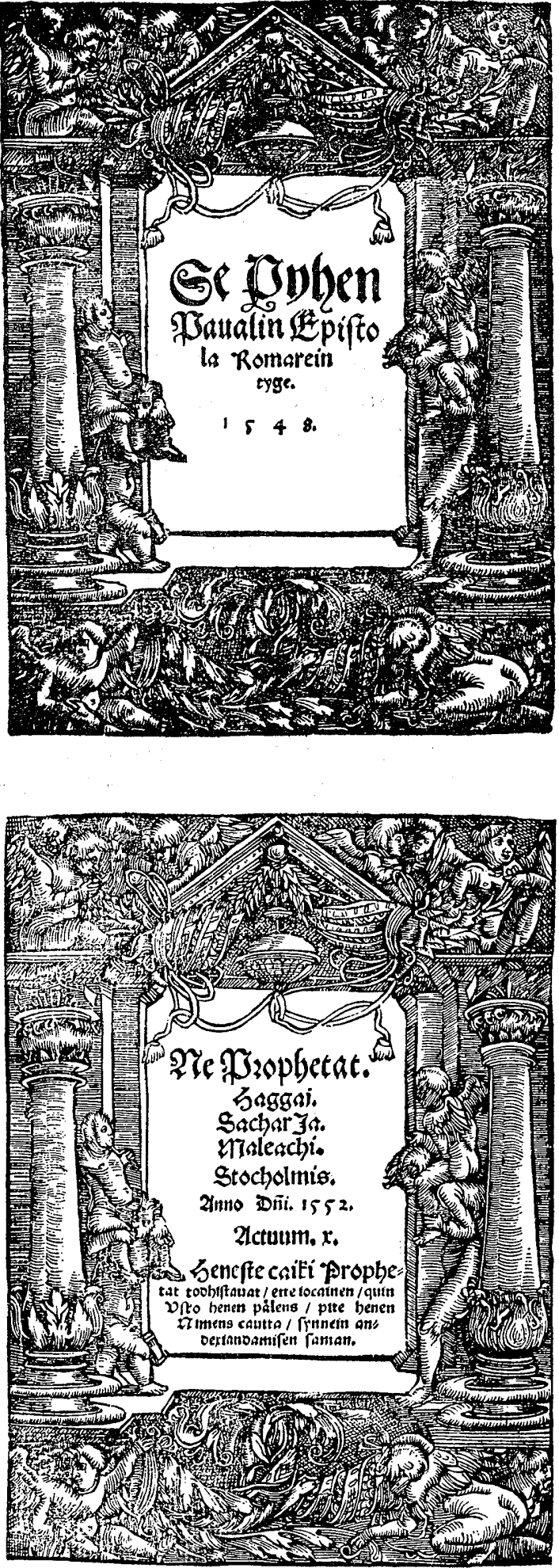
rinpojalta, antaisiko kuningas luvan Davidin Psalttarin ja myös muiden jumalanpalveluksessa ja seurakunnassa tarpeellisten Raamatun kirjain painattamiseen. Nämä seikat osoittavat, että Psalttarin painatustyö voitiin aloittaa aikaisintaan keväällä 1551. Psalttarin valmistumisesta on kirjan loppuun merkitty: Prentättu Stocholmis Amundi Lauritzan Poialda. Christusen Syndime Wodhesta. 1151, Augusti. 28. Näyttää siltä, että kirjan julkisuuteen saattamisessa on pidetty kiirettä, sillä Psalttarin painovirheiden luettelo on julkaistuna vasta Agricolan Weisut ja Ennustoxet-teoksen lopussa, joka ilmestyi pari kuukautta myöhemmin, nim. marraskuun 5. p:nä 1551.

Kun Psalttarin painatustyö siis alkoi keväällä 1551 ja päättyi saman vuoden elokuun lopussa, niin sen painatusvaiheissa ei voinut tapahtua sellaista talven aiheuttamaa työn keskeyttämistä eikä siis myöskään senkaltaisesta välikaudesta johtuvaa kirjan ilmestymistä kahtena eri osana, kuin profeettain kirjain painatusvaiheissa tapahtui.

Uskaltaisikohan näin ollen olettaa, että mestari Mikaelille olisi sattunut sellainen homeerinen torkahdus, että hän olisi tullut profeettain kirjain ohella maininneeksi Psalttarin toisena sellaisena teoksena, jonka painatus jouduttiin talven esteiden takia keskeyttämään ja julkaisemaan se kahtena osana, vaikka kysymyksessä olisikin ollut jokin muu hänen teoksensa?

Harkittavaksi nousee kysymys, mikä tämä muu Agricolan kirja olisi saattanut olla. Ainoat mahdolliset ovat hänen laajimmat teoksensa Rukouskirja ja Uusi testamentti.

Rukouskirjaa tarkastellessa huomaa, ettei se ole yhtenäinen kirja. Sisällykseltään se nimittäin jakautuu kahteen erilaiseen osaan. Alussa on suurelta osalta latinankielinen kalendaario, jota seuraa kohtia evankeliumeista. Varsinainen Rukouskirja alkaa vasta näköispainoksen sivulta 89. Siinä "Michael Olaui Agricola, Jumalan epekeluotoijn paluelia" esittää toivotuksensa papeille ym. Sitten seuraa esipuhe. Uuden painoarkin vaihdosta ei tässä kohdassa ole tapahtunut, vaan kirjan teksti jatkuu jo ennen esipuhetta aletulle arkille F. Varsinainen rukousosasto alkaa s. 103, jonka numeroksi on merkitty Plati I. Edellisellä sivulla on kustodi, ja painatusta on jatkettu aiemmin aletulle arkille. Kuva- ja tittelilehtiä kummassakaan käsitellyssä vaihdekohdassa s. 89 ja 103 ei ole. Näissä teoksen alkuosan ja varsinaisen rukouskirjaosan rajakohdissa ei siis näy mitään merkkiä siitä, että teos olisi julkaistu kahtena osana. Se tuntuu epätodennäköiseltä jo 
siitäkin syystä, että varsinaista rukouskirjaa edeltävä osa on siksi pieni, että sen eri osana julkaiseminen ei olisi tuntunut asialliselta.

Rukouskirjan painatustyö on päättynyt marraskuun 12:ntena 1544. Sen aloittamisesta ei tietääkseni ole säilynyt tietoja, mutta kun ottaa huomioon kirjan suuren koon, 861 sivua, niin ei voi kieltää sitä mahdollisuutta, että painatustyö olisi saatettu aloittaa jo edellisen vuoden 1543 puolella. Siihen ei kuitenkaan mikään suoranaisesti viittaa. Ei siis ole perusteita sille oletukselle, että Rukouskirja olisi ollut se toinen kirja, jota Agricola on tarkoittanut profeettain ohella. Toiseksi jää siis vain Uusi testamentti, joka on jo muilla perusteilla osoitettu sellaiseksi.

Agricolan Uuden testamentin ja profeettain kirjain (Weisüt ja Ennustoxet sekä Ne Prophetat. Haggai. SacharJa. Maleachi.) painatusvaiheiden toisiinsa liittämistä vahvistaa lisäksi eräs kummassakin ilmenevä yhtäläisyys. Edellä on tehty selkoa siitä, että UT:n osoitetussa jakokohdassa on Apostolien tekojen viimeisellä sivulla (II, s. 394 ) Lucas Cranachin piirtämä yleensä painetun kirjan lopussa tavattava käärmettä polkevaa Kristus-lasta esittävä kuva ja että sitä seuraavan Roomalaiskirjeen alussa on Georg Lembergerin piirtämä koristeellinen lehti, jossa on kirjeen nimi Se Pyhen Paualin Epistola Romarein tyge. 1548. Tämän lehden kääntösivulla alkaa epistolan Alcupuhe.

Kun tarkastelee profeettain ensiksi painettua osaa Weisut ja Ennustoxet, niin huomaa, että sen viimeisellä sivulla (III, s. 712) on sama Kristus-lapsen kuva kuin UT:n Apostolien tekojen lopussa ja että profeettain toisen osan Ne Prophetat alussa on kuvallinen nimilehti (III, s. 713), jonka koristekehys on täsmälleen samanlainen kuin UT:n Roomalaiskirjeen alussa oleva. Näille Ne Prophetatteoksen ja UT:n Roomalaiskirjeen nimilehdille on edelleen yhteistä se, että kummankin kääntösivuja on käytetty tekstin painamiseen. Näillä kääntösivuilla alkaa asianomaisen kirjan alkupuhe. Kuvat 1, 2 ja 3 , s. 125.

Puheena oleva kuva- ja nimilehtien samanlaisuus ymmärtääkseni osaltaan tukee sitä käsitystä, että Agricolan Ne Prophetat. Haggai. SacharJa. Maleachi. -teoksen alkupuheessa oleva viittaus Psalttarin ja profeettain painatusvaiheisiin perustuukin UT:n ja profeettain painatuksessa sattuneeseen keskeytykseen. Näin ollen Agricolan omiṣtakin lausumista voidaan saada lisätodisteita sille päätelmälle, johon 
jo edellä on eri perusteilla tultu, nimittäin että Mikael Agricolạn Uusi testamentti on ilmestynyt kahtena osana.

\section{Nillo Ixola: Über den Druck des Neuen Testaments von Mikael Agricola}

Mikael Agricolas Neues Testament aus dem Jahre 1548 hat auf der letzten Seite der Apostelgeschichte eine Zeichnung, die das Christuskind darstellt, wie es einer Schlange den Kopf zertritt. Derartige Bilder kommen im allgemeinen nur am Schluss eines Buches vor. Am Anfang des Römerbriefes, gleich nach der Apostelgeschichte, findet sich wieder ein dekoratives Titelblatt in der Art der Blätter am Anfang zweier anderer Bücher Mikael Agricolas. Das Auftaucher solcher Bilder mitteu im Neuen Testament veranlassten den Verfasser, sich etwas eingehender mit den Umständen im Zusammenhang mit dem Druck des Buches zu besehäftigen. 1547 wurde in Stockholm mit dem Druck begonnen. Die Ver-. bindungen zwischen Stockholm und Finnland hörteu aber in der Regel im Winter auf, weil das Meer zufror. Viele Zeichen weisen aber darauf hin, dass schon Ende 1547 der Beschluss vorgefasst wurde, den Druck mit der Apostelgeschichte abzuschliessen. In Frühjahr 1548 wurde die Arbeit wieder aufgenommen; man begann mit dem Römerbrief und legte ein Titelblatt ein. Diese Umstände weisen darauf hin, dass das Neue Testament in zwei Teilen erschien, obgleich weder in den Verzeichnissen über die finnische Literatur noch im Schrifttum, das sich mit Agricola und seinem Werk beschäftigt, dergleichen Erwähnungen vorkommen. Nur H. G. Porthan teilt in einem seiner Aufsätze (i.J. 1778) mit, Agricolas Neues Testament sei in zwei Teilen erschienen. Diese Mitteilung scheint in Vergessenheit geraten zu sein, bietet aber den Beobachtungen und Folgerungen des Verfassers einen beachtenswerten Halt. Auch das Vorwort von Agricolas Werk "Die Propheten Haggai. Sacharja. Maleachi" bietet weiteren Rückhalt für des Verfassers Schlussfolgerung, Agricolas Neues Testament sei in zwei Teilen erschienen. 